\title{
Neonatal Diabetes: How Research Unravelling the Genetic Puzzle Has both Widened Our Understanding of Pancreatic Development whilst Improving Children's Quality of Life
}

\author{
Julian P.H. Shield \\ University of Bristol and Bristol Royal Hospital for Children, Bristol, UK
}

\section{Key Words}

Neonatal diabetes, transient, permanent

\begin{abstract}
It has become increasingly apparent over the last few years that the seemingly ubiquitous auto-immune aetiology to pre-pubertal diabetes does not apply to those diagnosed under 6 months of age. In this age group, disease appears, in the vast majority of cases, to be conferred by single gene disorders mainly related to pancreatic development. The unravelling of these disorders has resulted in a far greater understanding of pancreatic development and some startling changes in treatment, resulting in improved quality of life and diabetes control. The progress made in our scientific and clinical understanding of these extremely rare diseases is a perfect example of how studying seemingly rare illnesses can improve our overall knowledge of much more common conditions.

Copyright $\odot 2007$ S. Karger AG, Basel
\end{abstract}

\section{Introduction}

The last 10 years have seen some remarkable advances in our understanding of the rare condition, neonatal diabetes. In a way perhaps not seen with all research into the genetic basis of diabetes, these advances have been mirrored by rapid improvements in the clinical management

\section{KARGER}

Fax +41613061234 E-Mail karger@karger.ch www.karger.com

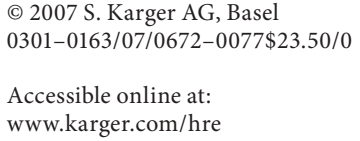

of many sufferers. Kitselle [1], originally described the condition in 1852, but the definition of neonatal diabetes has been arbitrary to say the least and is probably ripe for redefinition. In terms of age, it seems fair to suggest that a cut off for early-onset diabetes at 6 months is appropriate with diabetes developing before this age liable to be due to single gene mutations whilst above 6 months, classical autoimmune type 1 diabetes becomes by far and away the most common cause [2]. However, there are still clinical and theoretical reasons to classify early-onset diabetes as transient or permanent. For the sake of current convention and ease of reading this article will continue to use the terms transient neonatal diabetes (TNDM) and permanent neonatal diabetes (PNDM). As previously stated, the condition is rare, with an incidence of 1 : 400,000 live births in the United Kingdom [3]. The article will approach each condition in a historical framework to illustrate how our understanding of the many conditions underlying this disease has expanded. They are described in a historical sequence, based on the year in which an initial genetic basis was identified for each condition.

\section{Insulin Promoter Factor-1 Deficiency (OMIM 260370)}

In 1997, Stoffers et al. [4] described a child with PNDM and pancreatic exocrine insufficiency due to pancreatic agenesis [4]. The proband was identified as homozygous for a mutation (Pro63fsdelC) in insulin promoter factor-1 
(IPF-1), a gene involved in the master control of exocrine and endocrine pancreatic development, being responsible for the coordinated development of the pancreas in utero and also for the continued functional integrity of pancreatic $\beta$ islet cells. Furthermore, within the extended family were eight individuals in six generations with early-onset diabetes akin to type 2 diabetes. These were identified as heterozygotes for the same mutation with the mutant truncated isoform of IPF-1 acting as a dominant negative inhibitor of wild type IPF-1 activity. The illness resultant on heterozygosity was reassigned as $\mathrm{Ma}$ turity-Onset Diabetes of the Young (MODY) 4 [5]. Additional studies have also identified that less severe IPF-1 mutations can cause autosomal dominant late-onset forms of type 2 diabetes that account for around $6 \%$ of a French cohort of multiplex type 2 diabetic families [6]. Only one further case report of pancreatic agenesis has been ascribed to an IPF-1 mutation and this was a compound heterozygous mutation of the gene [7]. Due to the complete absence of pancreatic tissue, exocrine function is also compromised, requiring the use of pancreatic enzyme supplementation.

\section{Chromosome 6q Anomalies (OMIM 601410)}

Transient diabetes in infancy that resolves within the first 3 months of life is a well-recognised phenomenon. Clinically these children are born after significant intrauterine growth retardation, developing diabetes at a mean age of 3 days. The diabetes is characterised by severe hyperglycaemia and dehydration, but little or no ketosis [8]. This condition remains the most frequent single cause of neonatal diabetes [9].

In 1995, we identified two patients with paternal uniparental (iso)disomy of chromosome 6q24 causing transient neonatal diabetes [10]. Effectively, the child inherits two copies of the same chromosome 6 from the father with no contribution from the mother. The process of uniparental (iso)disomy can uncover autosomal recessive conditions, as the child can inherit two copies of a single mutation of a recessive gene carried on one of the parent of origin's chromosomes or it can imply that a gene or genes are imprinted, whereby the parent of origin effects a gene's functional phenotype. In simple terms, imprinted genes are switched off by the addition of a methyl group(s) generally in the promoter region, preventing gene transcription, which can either be on the maternal or paternal copy of a gene. $6 \mathrm{q}$ anomalies are due to disorders of imprinting. Two copies of paternal chromosome
6, an unbalanced duplication (extra copy) of paternal $6 \mathrm{q} 24[11,12]$ or loss of imprinting (loss of methylation) from maternal 6q24 all cause TNDM [13] due to over-expression of gene(s) within the TNDM locus. There are two potential imprinted genes responsible for TNDM at the 6q locus: $Z A C$ and/or HYMA1. We recently developed an over-expressing mouse model of the TNDM locus. This mouse displays many of the phenotypic features of $6 \mathrm{q}$ anomalies although birth weight was normal. We have shown that TNDM over-expression reduces the expression of the key transcription factor IPF-1 in the embryonic pancreas of these mice [14]. At the American Diabetes Association meeting this year, Polychronakos and Xiaoyu Du [15] presented data on specific and controlled $Z A C$ over-expression on $\beta$-cell function in the INS- 1 rat $\beta$-cell line, demonstrating that it was likely to be the gene responsible for TNDM in 6q anomalies.

All children with $6 \mathrm{q}$ anomalies have been associated with a transient form of diabetes in infancy, but this has been reported to relapse around the time of adolescence in a majority, although there probably is an element of reporting bias in the quoted levels of around $60 \%$ [8]. Interestingly, although the relapse is characterised by a loss of the classical insulin response to hyperglycaemia, we have some evidence that insulin is still available, as an excellent insulin response has been documented on glucagon stimulation suggesting the G-coupled protein receptor response remains intact through increasing cAMP and perhaps might be an area of therapeutic intervention in the future [16].

\section{Wolcott-Rallison Syndrome (OMIM 226980)}

Wolcott-Rallison Syndrome is an autosomal recessive disorder characterised by infancy-onset (often within the neonatal period) diabetes associated with a spondyloepiphyseal dysplasia. In addition, there is a constellation of other features such as hepatomegaly, mental retardation, renal failure and early death [17]. In 2000, Delepine et al. [18] used two consanguineous families to map the condition to the locus $2 \mathrm{p} 12$. Within this locus lay the gene EIF2AK3 that is highly expressed in islet cells acting as a regulator of protein synthesis. Proteins and insulin are manufactured in the endoplasmic reticulum. In response to environmental stresses, cells downregulate protein synthesis by phosphorylation of the $\alpha$-subunit of eukaryotic translation initiation factor-2 kinase 3 (eif2- $\alpha$ ) by eukaryotic translation initiation factor-2 kinase 3. Malfolded proteins in the endoplasmic reticulum inhibit fur- 
ther translation initiation mediated by increased phosphorylation of eif2- $\alpha$. A targeted mutation of the mouse Eif2ak3 gene (PERK) led to an accumulation of mal-folded proteins in the endoplasmic reticulum with resultant abnormally elevated protein synthesis and increased stress on endoplasmic reticulum folding machinery [19]. PERK is highly expressed in mouse pancreas. The PERK knock-out mouse demonstrates normal pancreatic endocrine and exocrine development. However, post-natally it develops endoplasmic reticulum distension accompanied by increased cell death and progressive diabetes mellitus and pancreatic exocrine failure [20]. Further analysis within the consanguineous WolcottRallison families confirmed frameshift or amino-acid substitution mutations occurring in EIF2AK3 segregating with the disorder in each family [18].

\section{IPEX (FOXP3 Mutations) (OMIM 304790)}

The scurfy mouse is a natural mutant clinically resembling human IPEX. Displaying an X-Linked recessive pattern of inheritance, the disease causes runting, ichthyosis, progressive anaemia, thrombocytopaenia, hypogonadism in males, increased infections and diarrhoea with death by $3-4$ weeks of age [21]. The disease is due to a mutation in the Foxp 3 gene encoding for a protein called 'scurfin' which is essential for normal immune homeostasis with scurfy T-cells being hyper-responsive to activation and resistant to cyclosporin. In 2001, the human disease was also identified as due to mutations in FOXP3 [22]. Entitled 'Immune dysregulation, polyendocrinopathy, enteropathy, X-Linked syndrome' (IPEX), its major features are early onset diabetes (often neonatal) and diarrhoea with small intestinal pathology such as villous atrophy and inflammatory infiltrate. The condition is probably the only one described in children developing diabetes under the age of 6 months in which autoimmunity plays a part. Type 1 diabetes auto-antibodies (GAD, IAA ,ICA) are frequently described as are those directed against the thyroid gland and various other organs [23]. Other features frequently described in the human condition other than diabetes, enteropathy and severe failure to thrive include eczema, haemolytic anaemia, thrombocytopaenia and hypothyroidism. Given that immune dysregulation appears to underlie this condition, the most obvious routes for treatment have been applied with varying degrees of success. Immunosuppression with cyclosporin or tacrolimus has proved to be of limited value in general although some patients have responded better than others [23]. The immuno-suppression has often been at the cost of significant medication toxicity to other organs such as the kidneys [24]. An alternative approach of bone marrow transplantation has been attempted in at least four cases with fairly promising effects in the short-term on diarrhoea, weight gain and possibly diabetes, but three patients have subsequently succumbed to infection often with evidence of an accompanying lymphoproliferative disorder [23, 25]. The fourth patient did not have diabetes nor a mutation in the coding region of FOXP3, but did have a deletion in the promoter upstream of the gene and reduced levels of FOXP3 mRNA. This child remains well, 16 months after transplantation with complete clinical and immunological remission [26]. Currently, the prognosis remains guarded for children with this condition.

\section{Glucokinase Mutations}

MODY2 is caused by mutations in the glucokinase gene and usually leads to mild hyperglycaemia in affected individuals. Glucokinase is a key regulator of glucose metabolism in islet cells controlling the levels of insulin secretion. However, within two families (one Norwegian, one Italian) with multiple forms of diabetes in their pedigree, two infants with classical PNDM (presenting on day one) were identified who were homozygous for missense mutations within the glucokinase gene rendering them completely deficient in glycolytic activity whilst their apparently consanguineous and mild to moderately glucose intolerant parents were heterozygous for the same mutations $[27,28]$. Further cases of permanent neonatal diabetes secondary to homozygous mutations in glucokinase have now been identified [29] although the condition is still very rare [30]. Although rare, I would recommend that if there is a history of maternal gestational diabetes, testing for fasting glucose levels in both parents is needed. If both parents have mild glucose intolerance a screen for glucokinase mutations is then warranted.

\section{KCNJ11 Permanent Neonatal Diabetes (OMIM *600937)}

The second most common cause of neonatal diabetes is that induced by heterozygous activating mutations in the KCNJ11 gene, which encodes the Kir 6.2 subunit of the $\mathrm{K}_{\mathrm{ATP}}$ channel, a critical regulator of $\beta$-cell insulin secretion [31]. Although the majority have been identified 
to cause permanent neonatal diabetes, a few have been associated with a transient condition akin to that caused by $6 \mathrm{q}$ anomalies [32]. In normal circumstances, the $\mathrm{K}_{\mathrm{ATP}}$ channel closes in response to increased intracellular ATP induced by glucose metabolism in the islet cell. In diabetes due to mutations in this gene, the channel displays decreased sensitivity to ATP and the $\beta$-cells remain hyperpolarised and unable to secrete insulin [33].

The babies are born small for gestational age, but not as small as in some other neonatal diabetes conditions (mean birth weight: 2,497 (690) g against 1,987 $\mathrm{g}(510)$ in $6 \mathrm{q}$ anomalies) [9]. Thirty percent have ketoacidosis and all display low insulin levels in the face of quite dramatic hyperglycaemia. The median age of presentation is around 3-4 weeks of age as opposed to 6q anomalies that tend to present in the first week of life although the spectrum in both conditions is such that birth weight or the age of presentation cannot be used to distinguish between the two conditions. About 20\% have associated neurological disease with developmental delay and sometimes epilepsy or muscle weakness reflecting a role for the same potassium channel in the central nervous system. The most severe end of this spectrum has been entitled 'DEND', Developmental delay, Epilepsy and Neonatal Diabetes in which children can be severely affected. There is also an intermediate condition (i-DEND) with milder developmental delay and no epilepsy. The mutations causing isolated diabetes produce less change in ATP sensitivity than those associated with diabetes and neurological disease (Q52R, V59G) [34].

Sulphonylureas, a class of drugs often used in type 2 diabetes, close $\mathrm{K}_{\mathrm{ATP}}$ channels by an ATP-independent mechanism. A number of patients with this condition have successfully transferred to oral sulphonylurea therapy needing a dose of between 0.5 and $1.0 / \mathrm{mg} / \mathrm{kg} /$ day of Glibenclamide [35,36], a relatively large dose compared to that used in adults with type 2 diabetes. The most extensive examination of this condition and response to sulphonylureas is currently in press. Within this paper are very necessary and informative physiological studies conducted on patients to improve understanding of the underlying disease process. The paper demonstrates that 90\% ( $\mathrm{n}=44 / 49$ : ages 3 months to 36 years) can be successfully transferred to oral therapy with a highly significant and sustained improvement in glycated haemoglobin (8.1-6.4\%). Although a successful switch to sulphonylureas is not mutation specific, it would appear that those with neurological features are less likely to be successful [37].
Personally, I have found transferring a case, one of the most rewarding experiences of my medical career. Over a 5-day period, we were able to transfer a 5-year-old child with permanent neonatal diabetes from twice daily insulin to Glibenclamide whilst improving his glycated haemoglobin from 8.3 to $5.2 \%$, abolishing his frequent hypoglycaemic attacks and apparently improving his neuro-cognitive development. Few experiences in medicine can be so dramatic.

\section{Permanent Neonatal Diabetes with Cerebellar Hypoplasia (OMIM 609069)}

In 1999, the author was one of a group identifying a new recessively inherited disease of neonatal diabetes associated with cerebellar hypoplasia [38]. The three children of consanguineous, Pakistani origin, had dysmorphic features (low set ears, triangular facies, talipes equinovarus and joint stiffness), associated with neonatal diabetes, microcephaly, recurrent apnoeic attacks and absent cerebellar tissue on brain imaging. A further child of North European descent was later identified with an identical phenotype in whom an autopsy demonstrated complete pancreatic agenesis. Further studies on this child and the original family led to the identification of the gene responsible, PTF1A. This gene encodes the pancreas transcription factor $1 \alpha$ which is essential for normal pancreatic and cerebellar development [39]. So far, all children described with this condition have died in infancy, not from diabetes but associated respiratory failure probably secondary to the brain anomalies.

\section{Other Very Rare Forms of Neonatal Diabetes}

(i) In humans it has been shown that heterozygous mutations of the HNF-1 $\beta$ gene are associated with a form of MODY5, which is characterised by dominantly inherited diabetes mellitus associated with renal cysts. In one family, a missense heterozygous mutation of $H N F-1 \beta$ was associated with permanent neonatal diabetes and some small cysts in one child but only transient hyperglycaemia with more profound renal dysplasia in the other sibling [40].

(ii) In 2004, a probable new autosomal recessive condition of neonatal diabetes with intestinal and biliary anomalies was described. The children $(n=5)$ were all small for gestational age with neonatal diabetes, atresia of duodenum, jejunum and gall-bladder and absence of in- 
Table 1. Main types of neonatal diabetes, their genetic basis, co-morbidities, treatment, outcome and relative frequencies as potential diagnoses

\begin{tabular}{|c|c|c|c|c|}
\hline Gene & Chromosome & Associated features & Outcome and treatment & $\begin{array}{l}\text { Frequency of reports and } \\
\text { clinical likelihood }\end{array}$ \\
\hline$I P F-1$ & $13 q 21.1$ & Pancreatic agenesis & $\begin{array}{l}\text { Insulin and exocrine replacement ther- } \\
\text { apy for life, outcome seemingly good }\end{array}$ & Rare \\
\hline $\begin{array}{l}\text { Probable } \\
Z A C\end{array}$ & $6 \mathrm{q} 24$ & Macroglossia and umbilical herniae & $\begin{array}{l}\text { Resolution usually within } 3 \text { months. } \\
\text { Relapse around adolescence in } \approx 50 \%\end{array}$ & $\begin{array}{l}\text { Commonest form of tran- } \\
\text { sient neonatal diabetes }\end{array}$ \\
\hline FOXP3 & Xp11.23 & $\begin{array}{l}\text { Enteropathy with severe failure to } \\
\text { thrive, other autoimmune phenomena } \\
\text { such as hypothyroidism and auto- } \\
\text { immune haemolytic anaemia }\end{array}$ & $\begin{array}{l}\text { Poor prognosis } \\
\text { Bone marrow transplantation and } \\
\text { immuno-suppression have been tried } \\
\text { with equivocal success }\end{array}$ & Fairly common \\
\hline Glucokinase & $7 \mathrm{p} 15-13$ & None identified & Life-long insulin therapy & Relatively rare \\
\hline EIF2AK3 & $2 \mathrm{p} 12$ & $\begin{array}{l}\text { Renal insufficiency, mental retarda- } \\
\text { tion, hepatomegaly, spondyloepiphy- } \\
\text { seal dysplasia }\end{array}$ & Early death, diabetes requires insulin & Fairly common \\
\hline PTF1A & $10 \mathrm{p} 12.3$ & $\begin{array}{l}\text { Joint contractures, 'beaked nose' and } \\
\text { low set dysplastic ears: absent pancreas } \\
\text { at post-mortem }\end{array}$ & Early death from respiratory failure & Rare \\
\hline KCN11J & $11 \mathrm{p} 15.1$ & $\begin{array}{l}\text { Severe mutations have associated } \\
\text { neurological features such as epilepsy } \\
\text { and learning difficulties (DEND) }\end{array}$ & $\begin{array}{l}\text { Majority respond to treatment with } \\
\text { sulphonylureas }(90 \%)\end{array}$ & $\begin{array}{l}\text { Commonest form of per- } \\
\text { manent neonatal diabetes } \\
\text { and rarer form of tran- } \\
\text { sient neonatal diabetes }\end{array}$ \\
\hline$H N F-1 \beta$ & 17 cen-q21.3 & Renal cysts & Long-term insulin therapy & Rare \\
\hline GLIS3 & $9 p$ & $\begin{array}{l}\text { Congenital hypothyroidism and } \\
\text { glaucoma. Liver fibrosis and cystic } \\
\text { kidney disease. Facial dysmorphism }\end{array}$ & $\begin{array}{l}50 \% \text { dead by } 2 \text { years of age. } \\
\text { Oldest surviving case now aged } \\
22 \text { ears. }\end{array}$ & Rare (3 families, 6 cases) \\
\hline
\end{tabular}

sulin, glucagon and somatostatin-containing cells on pancreatic post-mortem examination. Four of the five died in the first year of life from seemingly multi-organ failure and/or sepsis [41].

(iii) Interestingly, a similar but possibly different disease has been described with pancreatic agenesis, absent gall-bladder and cardiac septal anomalies $[42,43]$. In neither case an IPF-1 gene mutation was identified, suggesting further disorders in a gene(s) upstream of $I P F-1$ in pancreatic development.

(iv) In June 2006, Senee et al. [44] described a frameshift mutation or deletions in the transcription factor GLIS3 in three consanguineous families with a history of neonatal diabetes, congenital hypothyroidism and facial dysmorphology (large, flat, square-shaped face with a thin and bird-shaped curved nose). Additional features seen in some, but not all patients included congenital glaucoma, liver fibrosis and cystic kidneys.

\section{Treatment Options in Neonatal Diabetes}

In my opinion, all neonates presenting acutely with diabetes should be started on insulin therapy: usually on a continuous infusion so that normoglycaemia and any metabolic decompensation such as acidosis can be addressed swiftly. Once stabilised and an approximately daily requirement of insulin is established, conversion to either subcutaneous, intermittent insulin or continuous pump therapy can be initiated. Although long-acting insulins especially the analogue glargine may prove useful in a basal bolus regimen [45], the best results seem to be obtained using continuous insulin pump therapy [46].

On occasion, when pump therapy has proved logistically difficult, I have used a three times a day mixed insulin regimen at mealtimes with some success in those babies undergoing weaning. In the case of $6 \mathrm{q}$ anomalies, diabetes will be transient but insulin is required until re- 
mission to prevent dehydration and allow normal growth. If a molecular diagnosis of a $6 \mathrm{q}$ anomaly is established early in a baby with reasonable glycaemic control, it is tempting to use intermittent subcutaneous injections until remission as education of the parents in pump therapy can be lengthy and complicated and the diabetes classically resolves over a few weeks or months.

In permanent neonatal diabetes due to conditions other than Kir 6.2 mutations, responding so well to sulphonylureas, insulin is also required long-term and a pump seems likely to be the best choice for optimal diabetes control. I do not feel that an empirical trial of sulphonylurea therapy in babies with neonatal diabetes is indicated until such time as an established molecular diagnosis of a Kir 6.2 mutation has been made. If such a diagnosis is made, it has been my policy to conduct the transfer to sulphoylureas from insulin as a hospital in-patient to allow adequate monitoring of blood glucose and ketosis through the transitional period (table 1).
Failure to grow with adequate glycaemic control in any condition should alert the physician to the possibility of exocrine failure which can be a feature of some causes of permanent neonatal diabetes and has even been described, although rarely, in the transient form [47].

\section{Conclusions}

Neonatal diabetes has proved an informative, natural model demonstrating the role of key genes in pancreatic development. Furthermore, our understanding of the pathophysiology underlying these conditions has led to innovative and improved therapy for some children. Undoubtedly, neonatal diabetes has yet more to tell us in future [48].

\section{References}

1 Kitselle: Jb Kinderheilk 1852;18.

$\checkmark 2$ Iafusco D, Stazi MA, Cotichini R, et al: Permanent diabetes mellitus in the first year of life. Diabetologia 2002;45:798-804.

3 Shield JP, Gardner RJ, Wadsworth EJ, et al: Aetiopathology and genetic basis of neonatal diabetes. Arch Dis Child Fetal Neonatal Ed 1997;76:F39-F42.

$\checkmark 4$ Stoffers DA, Zinkin NT, Stanojevic V, Clarke WL, Habener JF: Pancreatic agenesis attributable to a single nucleotide deletion in the human IPF1 gene coding sequence. Nat Genet 1997;15:106-110.

5 Stoffers DA, Stanojevic V, Habener JF: Insulin promoter factor-1 gene mutation linked to early-onset type 2 diabetes mellitus directs expression of a dominant negative isoprotein. J Clin Invest 1998;102:232-241.

$\checkmark 6$ Hani EH, Stoffers DA, Chevre JC, et al: Defective mutations in the insulin promoter factor-1 (IPF-1) gene in late-onset type 2 diabetes mellitus. J Clin Invest 1999;104:R41R48.

7 Schwitzgebel VM, Mamin A, Brun T, et al: Agenesis of human pancreas due to decreased half-life of insulin promoter factor 1 . J Clin Endocrinol Metab 2003;88:43984406.

$\checkmark 8$ Temple IK, Gardner RJ, Mackay DJ, Barber JC, Robinson DO, Shield JP: Transient neonatal diabetes: widening the understanding of the etiopathogenesis of diabetes. Diabetes 2000;49:1359-1366.
>9 Slingerland AS, Hattersley AT: Mutations in the Kir6.2 subunit of the KATP channel and permanent neonatal diabetes: new insights and new treatment. Ann Med 2005;37:186195. Temple IK, James RS, Crolla JA, et al: An im-
printed gene(s) for diabetes? Nat Genet 1995; 9:110-112.

11 Temple IK, Gardner RJ, Robinson DO, et al: Further evidence for an imprinted gene for neonatal diabetes localised to chromosome 6q22-q23. Hum Mol Genet 1996;5:11171121.

12 Cave H, Polak M, Drunat S, Denamur E, Czernichow P: Refinement of the $6 \mathrm{q}$ chromosomal region implicated in transient neonatal diabetes. Diabetes 2000;49:108-113. 13 Gardner RJ, Mackay DJ, Mungall AJ, et al: sient neonatal diabetes mellitus. Hum Mol Genet 2000;9:589-596.

14 Ma D, Shield JP, Dean W, et al: Impaired glucose homeostasis in transgenic mice expressing the human transient neonatal diabetes mellitus locus, TNDM. J Clin Invest 2004;114:339-348.

15 Polychronakos C, Xiaoyu D: Graded Overexpression of ZAC Impairs Glucose Stimulated Insulin Secretion in Beta-Cells. Washington, American Diabetes Association, 2006, 190-OR
16 Valerio G, Franzese A, Salerno M, et al: Betacell dysfunction in classic transient neonatal diabetes is characterized by impaired insulin response to glucose but normal response to glucagon. Diabetes Care 2004;27:24052408.

17 Senee V, Vattem KM, Delepine M, et al: Wolcott-Rallison Syndrome: clinical, genetic, and functional study of EIF2AK3 mutations and suggestion of genetic heterogeneity. Diabetes 2004;53:1876-1883.

18 Delepine M, Nicolino M, Barrett T, Golamaully M, Lathrop GM, Julier C: EIF2AK3, encoding translation initiation factor 2-alpha kinase 3, is mutated in patients with Wolcott-Rallison syndrome. Nat Genet 2000;25:406-409.

19 Harding HP, Zhang Y, Bertolotti A, Zeng H, Ron D: Perk is essential for translational regulation and cell survival during the unfolded protein response. Mol Cell 2000;5:897-904.

20 Harding HP, Zeng H, Zhang Y, et al: Diabetes mellitus and exocrine pancreatic dysfunction in perk-/- mice reveals a role for translational control in secretory cell survival. Mol Cell 2001;7:1153-1163.

21 Brunkow ME, Jeffery EW, Hjerrild KA, et al: Disruption of a new forkhead/winged-helix protein, scurfin, results in the fatal lymphoproliferative disorder of the scurfy mouse. Nat Genet 2001;27:68-73. 
22 Wildin RS, Ramsdell F, Peake J, et al: Xlinked neonatal diabetes mellitus, enteropathy and endocrinopathy syndrome is the human equivalent of mouse scurfy. Nat Genet 2001;27:18-20.

-23 Wildin RS, Smyk-Pearson S, Filipovich AH: Clinical and molecular features of the immunodysregulation, polyendocrinopathy, enteropathy, X linked (IPEX) syndrome. J Med Genet 2002;39:537-545.

24 Ruemmele FM, Brousse N, Goulet O: Autoimmune enteropathy: molecular concepts. Curr Opin Gastroenterol 2004;20:587-591.

25 Baud O, Goulet O, Canioni D, et al: Treatment of the immune dysregulation, polyendocrinopathy, enteropathy, X-linked syndrome (IPEX) by allogeneic bone marrow transplantation. N Engl J Med 2001;344: 1758-1762.

26 Mazzolari E, Forino C, Fontana M, et al: A new case of IPEX receiving bone marrow transplantation. Bone Marrow Transplant 2005;35:1033-1034.

-27 Njolstad PR, Sovik O, Cuesta-Munoz A, et al: Neonatal diabetes mellitus due to complete glucokinase deficiency. N Engl J Med 2001; 344:1588-1592.

28 Njolstad PR, Sagen JV, Bjorkhaug L, et al: Permanent neonatal diabetes caused by glucokinase deficiency: inborn error of the glucose-insulin signaling pathway. Diabetes 2003:52:2854-2860.

-29 Porter JR, Shaw NJ, Barrett TG, Hattersley AT, Ellard S, Gloyn AL: Permanent neonatal diabetes in an Asian infant. J Pediatr 2005; 146:131-133.

-30 Gloyn AL, Ellard S, Shield JP, et al: Complete glucokinase deficiency is not a common cause of permanent neonatal diabetes. Diabetologia 2002;45:290.

-31 Gloyn AL, Pearson ER, Antcliff JF, et al: Activating mutations in the gene encoding the ATP-sensitive potassium-channel subunit Kir6.2 and permanent neonatal diabetes. $\mathrm{N}$ Engl J Med 2004;350:1838-1849.
2 Gloyn AL, Reimann F, Girard C, et al: Relapsing diabetes can result from moderately activating mutations in KCNJ11. Hum Mol Genet 2005;14:925-934.

33 Hattersley AT, Ashcroft FM: Activating mutations in Kir6.2 and neonatal diabetes: new clinical syndromes, new scientific insights, and new therapy. Diabetes 2005;54:25032513.

34 Proks P, Antcliff JF, Lippiat J, Gloyn AL, Hattersley AT, Ashcroft FM: Molecular basis of Kir6.2 mutations associated with neonatal diabetes or neonatal diabetes plus neurological features. Proc Natl Acad Sci USA 2004; 101:17539-17544.

35 Sagen JV, Raeder H, Hathout E, et al: Permanent neonatal diabetes due to mutations in KCNJ11 encoding Kir6.2:patient characteristics and initial response to sulfonylurea therapy. Diabetes 2004;53:2713-2718.

36 Klupa T, Edghill EL, Nazim J, et al: The identification of a R201H mutation in KCNJ11, which encodes Kir6.2, and successful transfer to sustained-release sulphonylurea therapy in a subject with neonatal diabetes: evidence for heterogeneity of beta cell function among carriers of the R201H mutation. Diabetologia 2005;48:1029-1031.

37 Pearson EFI, Njolstad P, Malecki M, Flanagan S, Larkin B, Ashcroft F, Klimes I, Codner $\mathrm{E}$, Iotova V, Slingerland A, Shield J, Robert J-J, Holst J, Clark P, Ellard S, Sovik O, Polak $\mathrm{M}$, Hattersley A: Switching from insulin to oral sulfonylureas in patients with diabetes due to Kir6.2 mutations. New Engl J Med 2006;355:467-477.

38 Hoveyda N, Shield JP, Garrett C, et al: Neonatal diabetes mellitus and cerebellar hypoplasia/agenesis: report of a new recessive syndrome. J Med Genet 1999;36:700-704.
39 Sellick GS, Barker KT, Stolte-Dijkstra I, et al: Mutations in PTF1A cause pancreatic and cerebellar agenesis. Nat Genet 2004;36: 1301-1305.

40 Yorifuji T, Kurokawa K, Mamada M, et al: Neonatal diabetes mellitus and neonatal polycystic, dysplastic kidneys: phenotypically discordant recurrence of a mutation in the hepatocyte nuclear factor-1beta gene due to germline mosaicism. J Clin Endocrinol Metab 2004;89:2905-2908.

41 Mitchell J, Punthakee Z, Lo B, et al: Neonatal diabetes, with hypoplastic pancreas, intestinal atresia and gall bladder hypoplasia: search for the aetiology of a new autosomal recessive syndrome. Diabetologia 2004;47: 2160-2167.

42 Verwest AM, Poelman M, Dinjens WN, et al: Absence of a PDX-1 mutation and normal gastroduodenal immunohistology in a child with pancreatic agenesis. Virchows Arch 2000;437:680-684.

43 Ashraf A, Abdullatif H, Hardin W, Moates JM: Unusual case of neonatal diabetes mellitus due to congenital pancreas agenesis. Pediatr Diabetes 2005;6:239-243.

44 Senee V, Chelala C, Duchatelet S, et al: Mutations in GLIS3 are responsible for a rare syndrome with neonatal diabetes mellitus and congenital hypothyroidism. Nat Genet 2006; 38:682-687.

45 Jeha GS, Venkatesh MP, Edelen RC, Kienstra KA, Karaviti L, Fernandes CJ: Neonatal diabetes mellitus: patient reports and review of current knowledge and clinical practice. J Pediatr Endocrinol Metab 2005;18:10951102.

46 Polak M, Shield J: Neonatal and very-earlyonset diabetes mellitus. Semin Neonatol 2004;9:59-65.

47 Fosel S: Transient and permanent neonatal diabetes. Eur J Pediatr 1995;154:944-948.

48 Sperling MA: Neonatal diabetes mellitus: from understudy to center stage. Curr Opin Pediatr 2005;17:512-518. 